\title{
3D IMAGING SYSTEM FOR THE INTELLIGENT EXCAVATION SYSTEM (IES)
}

\author{
M. J. Chae \\ Korea Institute of Construction Technology \\ 2311, Daehwa-Dong, Ilsangseo-Gu, Goyang-Si \\ chae@kict.re.kr

\section{J. R. Kim} \\ Korea Institute of Construction Technology \\ 2311, Daehwa-Dong, Ilsangseo-Gu, Goyang-Si \\ jrkim@kict.re.kr

\section{J. H. Jang} \\ Doosan Infracore \\ 39-3, Sungbok-Dong, Yongin-Si, Gyeonggi-Do \\ junehyun.jang@doosan.com
}

\author{
H. S. Yoo \\ Inha University \\ 2S429A, 253, Yonghyun-Dong, Nam-Gu, Incheon \\ hsyoo.inha@gmail.com \\ M. Y. Cho \\ Korea Institute of Construction Technology \\ 2311, Daehwa-Dong, Ilsangseo-Gu, Goyang-Si \\ mycho@kict.re.kr \\ D. S. Jang \\ Doosan Infracore \\ 39-3, Sungbok-Dong, Yongin-Si, Gyeonggi-Do \\ dalsik.jang@doosan.com
}

\begin{abstract}
There have been many efforts in automatic object recognition using computing technologies. Especially, in the development of automated construction equipment, automatic object recognition is very important issue for the proper equipment maneuvering. 3D imaging system was used, which employs the TOF (time-of-flight) of a laser to measure the distances of millions of points and creates three-dimensional (3D) point data. Authors studied the specifications of 3D imaging systems and demonstrated three bestselling systems in a real civil earth work site to test their compatibility with the civil earth work environment. By comparing the specifications of the systems and by virtue of a field test, an optimum 3D imaging system was chosen. Finally, a customized software user interface (UI) was developed for the chosen 3D imaging system. The customization requirements were reviewed and the UI customization was coded. A new application was also developed specifically for the IES project.
\end{abstract}

\section{KEYWORDS}

3D imaging system, Earth work environment modelling 


\section{INTRODUCTION}

Since the Industrial Revolution, the productivity of all industrial areas has grown together with the development of science and technology. The productivity of construction technology has also been spurred, but is almost reaching the limit due to the high level of human involvement in it. The productivity of the construction process largely depends on the skill of the workers. On the whole, the productivity of the construction industry showed less than 5\% growth from 1991 to 2007 , which is very low compared to the $35 \%$ growth in the car industry. Due to the non-repetitive characteristic of the construction industry, contrary to the manufacturing industry, which is based on simple repetition, the level of automation in the field is very low. In addition, the construction industry has a high risk of accidents.

Considering the lack of skilled engineers, the low automation rate, and the high death rate from industrial disasters in the construction industry, its automation is inevitable [1].

The authors are currently implementing the IES (Intelligent Excavation System) project, a multimillion-dollar project of KICTTEP. The IES Project's ultimate objective is the automation of excavators in earth works. It has three main research segments: (1) on an intelligent task planning system; (2) on a work environment recognition and intelligent control system; and (3) on the intelligent excavation system integration. In this paper, the brain of IES, intelligent task planning, is considered, and the "eye" of IES is especially presented.

The technology for the effective modeling of objects around the work environment and for automatic recognition is the first indispensable step in an automation or intelligent process [2]. It started with simple sensors and produced many results, including a vision system using a camera and a $3 \mathrm{D}$ modeling system using a broad-area 3D laser scanner, continuing efforts to realize better environment recognition. The most practical recognition technology ever is the vision system used in various industrial areas, which extracts and recognizes large amounts of information from image data taken with a camera [3]. The vision system using a camera is barely available in large-area environments, however, as in earth works, and has low reliability in terms of distance coordinates, which makes it unsuitable for accurate modeling of broad-area environments. On the contrary, 3D imaging system facilitates easy 3D modeling of large areas, shows high accuracy, and is durable, making it sufficient for outdoor environments.

3D imaging systems usually use the TOF (time-offlight) of laser to measure the distances of millions of points, and creates three-dimensional point data called point clouds. The IES Project does not develop a new 3D imaging system. Instead, the authors bought an off-the-shelf 3D imaging system and customized it. They studied the specifications of 3D imaging systems and demonstrated three bestselling systems in a real civil earth work site to test their compatibility with civil earth work environments. By comparing the specifications and by virtue of a field test, an optimum system was chosen.

Finally, a customized software user interface (UI) was developed for the chosen 3D imaging system. The customization requirements were reviewed and the UI customization was coded, and a new application was developed specifically for the IES project.

\section{METHODOLOGY AND SCOPE}

This study was conducted for 3D modeling of earth works environments using 3D imaging system. This study covers a 3D imaging system performance analysis, the concept design of a 3D modeling system optimized for earth works, and software development for 3D imaging system device control and automatic collection and arrangement of $3 \mathrm{D}$ data. The software was simplified and automated, to which only the functions optimized to and required for earth works were added. This study was processed according to the following steps: (1) The international market and domestic usage of broadarea 3D laser scanners were studied via literature; (2) The performance of broad-area 3D laser scanners that can be supplied to the domestic market was analyzed via field simulation, and a 3D imaging system suitable for earth works was selected; (3) 
The hardware and software concepts of a 3D work environment modeling system were designed, and a methodology for 3D data acquisition in the field was suggested; (4) The detailed functions of a 3D work environment modeling software and user interface were designed; (5) 3D scanning data were acquired in the actual earth works field, and after 3D modeling, the accuracy of the $3 \mathrm{D}$ modeling was tested by comparing its results with those of the total station.

\section{3D IMAGING SYSTEM EVLUATION}

To choose the most suitable device for earth works, a test at an earth works field was conducted with three kinds of products. The test was conducted at Youngshin Construction's apartment building construction site in Pangyo. The test subjects were products of Leica HDS (Switzerland), Riegl (Austria), and Trimble (USA), which are the bestselling products in the field. 3D modeling was repeatedly performed for an identical field with a time interval (Figure 1).

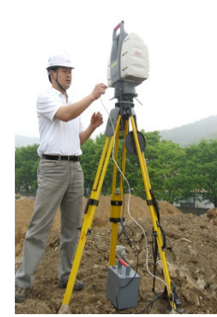

Leica

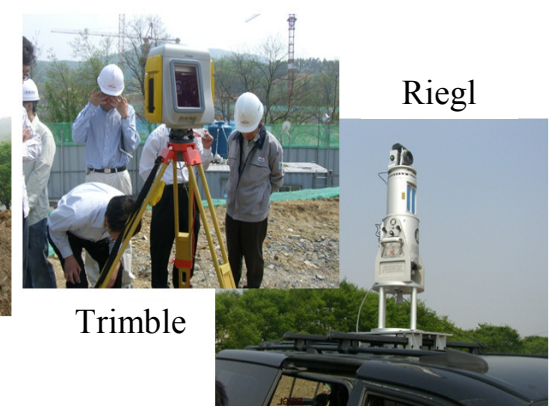

Figure 1. Three Imaging Systems Tested
LMS-Z210ii of Riegl has a relatively fast scanning speed of 12,000 points/second and an independent operating software, and provides an API for thirdparty customization. Its distance is $650 \mathrm{~m}$ at $80 \%$ reflectivity, which is the longest, but it is deemed that 200 300 m will be sufficient, from the analysis in the actual earth works field. It has the greatest volume and weight, with relatively low accuracy (10 $\mathrm{mm}$ at $50 \mathrm{~m}$ ), and an additional camera module is required for photogrammetry, which is indispensable for object recognition.

Scanstation 2 of Leica has the fastest speed of 50,000 points/second and relatively high accuracy (4 $\mathrm{mm}$ at $50 \mathrm{~m}$ ), and provides partner institutions an operating software and an API for development. Its distance is $300 \mathrm{~m}$ at $90 \%$ reflectivity, which is at the midpoint, and a digital camera is embedded in it so that it can be used in photogrammetry without additional modules. Leica has a significant domestic market share and provides effective service support.

ILRIS-3D of Trimble (Optech) has the lowest speed of 2,000 points/sec, and its distance is the longest at $1,500 \mathrm{~m}$ at $80 \%$ reflectivity. It does not provide an operating software and an API, however, nor a slope calibration function.

Consequently, it was found that a scanning distance of $200 \sim 300 \mathrm{~m}$ at an actual earth works field is sufficient, and that accuracy and speed are more important than distance. As a result, Scanstation II of Leica was determined to be the most suitable device, being appropriate for photogrammetry and providing an API.

\section{3D WORK ENVIRONMENT MODELING SYSTEM CONCEPT DESIGN}

For 3D modeling of work environments in the earth works field, the structure, process, and detailed specifications of a 3D work environment modeling system were designed in this study. The hardware of the 3D work environment modeling system comprises a field SUV, a 3D scanner, a GPS, a wireless transceiver, an industrial notebook PC, a tripod, a battery pack, and a recognition target, as shown in Figure 2. The industrial notebook PC controls the $3 \mathrm{D}$ scanner, processes $3 \mathrm{D}$ point cloud data, determines the absolute coordinates using GPS location data, and transmits the resulting processed data to the wireless transceiver. A $3 \mathrm{D}$ scanner is mounted using a loop open device and a telescoping device so that it can be completely controlled at the driver's position in the field vehicle.

As for the software, Cyclone 5.8 API of Leica HDS and RapidForm XOV API, developed by a domestic enterprise, Inus Tech., were used to realize the 3D work environment modeling system. The cyclone 5.8 API is the first of its kind in Korea. It completely controls a $3 \mathrm{D}$ scanner without using the software basically provided in the $3 \mathrm{D}$ scanner, and is the base for the development of a unique earth works 
modeling system. RapidForm XOV's functions include $3 \mathrm{D}$ processing such as mesh creation, filtering, and registration of 3D point clouds acquired from the 3D scanner, and analytical functions such as on volume, distance, and deviation.

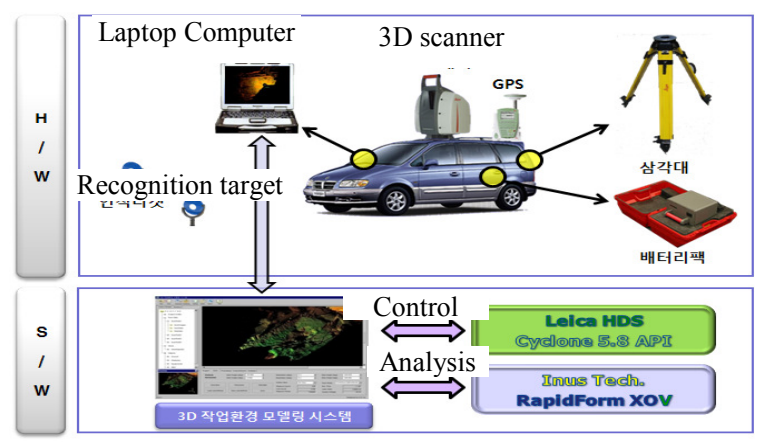

Figure 2. Vehicle-mounted 3D imaging system and work environment modeling concept

It was basically assumed that the topographical changes in the earth works field were scanned at 3 5 points at a time and 2 3 times a day for a certain work field, as shown in Figure 3. To register the scanning results for various positions as one, a recognition target had to be installed at a position where it could be recognized from each position, in such a manner that the driver could perform $3 \mathrm{D}$ scanning, processing, and data transmission.

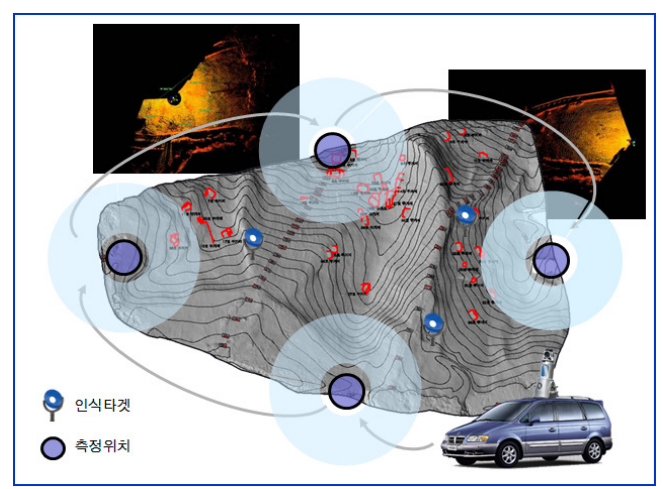

Figure 3. Scanning at multiple locations and registration

\section{USER INTERFACE DESIGN FOR 3D MODELING SOFTWARE}

The functions of the 3D modeling software and user interface, which are the core parts of the 3D work environment modeling system, were designed in this study. The following picture shows the initial window, which includes project management functions such as the creation, saving, and removal of a new project.

In the initial project configuration module, basic field information can be entered after the creation of a new project, and includes a 3D scanner connection and detailed setting of the GPS.

Figure 4 shows a module that includes the functions of driving a scanner and performing the scanning in the field, displays the scanning results, and controls the setting values such as the scanning scope and resolution.

Figure 5 shows the functions that filter and process the scanned point cloud, register the point cloud at various angles, and convert the result into a mesh surface, a solid, etc.

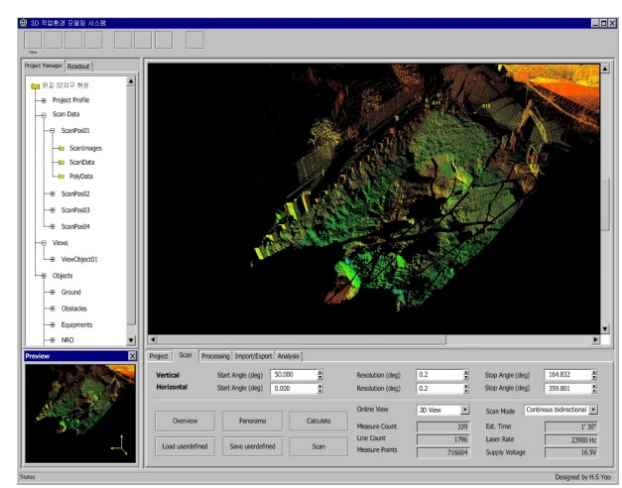

Figure 4. 3D scanner controller window

The completed topographical data is can be imported/exported in 3D CAD and ASCII type data. Distance measurement, and earth volume can be measured. 


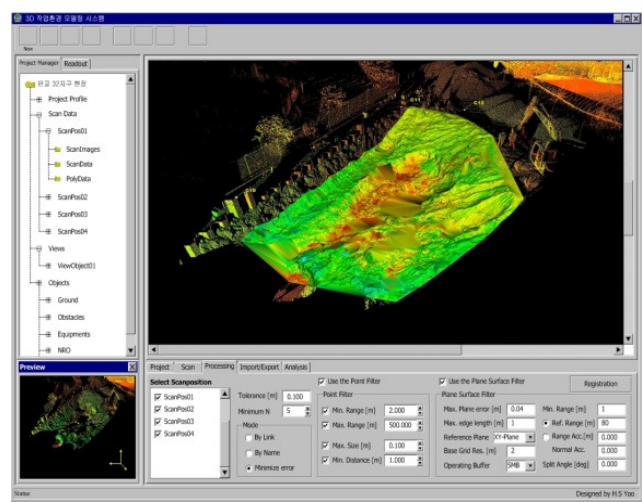

Figure 5. Data processing

\section{ACCURACY TEST OF 3D IMAGING SYSTEM}

A modeling accuracy test for the 3D modeling system prototype was conducted on an actual earth works field (Eunpyeong New Town Project field by Youngshin Construction). Six recognition targets (Center, A, B, C, D, and E) were installed (Figure 6), and the relative distances between the targets were measured using a 3D scanner and a total station to measure the errors. The scanning was conducted at two points using a 3D scanner; the two scanned data were registered into a $3 \mathrm{D}$ model; and the targets were manually recognized to measure the distance between the positions. A total station was used to measure the distances of six points at a position outside the test area to measure the relative distances. As shown in Table 1, the maximum error of the distances between the targets was $29 \mathrm{~mm}$ at $76.8 \mathrm{~m}$, and the average error per meter was $0.256 \mathrm{~mm}$.

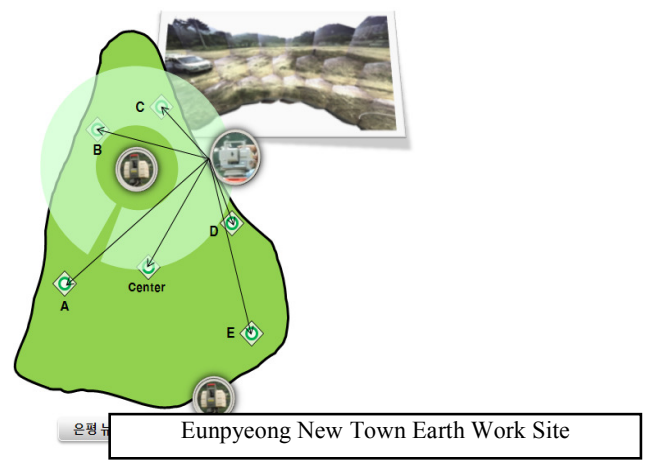

Figure 6. Scanner position marked on the field topography
The higher-than-expected errors are thought to be because the prism targets of the 3D scanner and the total station are different, and because scanning station-I, which has a low accuracy, was used in this study. Therefore, a linear error value will later be tested in the earth works field, with a no-target type of total station and more targets at a specific interval. Figure 7 shows the measurement of the distances between the targets using 3D modeling with acquired data.

Table 1 Measurement of Distance between Targets

\begin{tabular}{|c|c|c|c|c|}
\hline $\begin{array}{c}\text { Distanc } \\
\mathrm{e}\end{array}$ & $\begin{array}{c}\text { Total } \\
\text { Station } \\
(\mathrm{m})\end{array}$ & $\begin{array}{c}\text { Scan } \\
\text { Station } \\
(\mathrm{m})\end{array}$ & $\begin{array}{c}\text { Error } \\
(\mathrm{m})\end{array}$ & $\begin{array}{c}\text { Error per } \\
\text { Meter }(\mathrm{mm})\end{array}$ \\
\hline$\square-\mathrm{A}$ & 34.829 & 34.838 & -0.009 & -0.27198 \\
\hline$\square-\mathrm{B}$ & 56.911 & 56.891 & 0.020 & 0.352569 \\
\hline$\square-\mathrm{C}$ & 70.804 & 70.788 & 0.016 & 0.225115 \\
\hline$\square-\mathrm{D}$ & 33.162 & 33.155 & 0.007 & 0.21449 \\
\hline$\square-\mathrm{E}$ & 36.226 & 36.238 & -0.012 & -0.33549 \\
\hline A-B & 60.725 & 60.733 & -0.008 & -0.12465 \\
\hline B-C & 27.471 & 27.467 & 0.004 & 0.131137 \\
\hline C-D & 76.825 & 76.796 & 0.029 & 0.375151 \\
\hline D-E & 39.495 & 39.511 & -0.016 & -0.41178 \\
\hline E-A & 55.602 & 55.607 & -0.005 & -0.08332 \\
\hline Total & 492,049 & 492,024 & $\mid 0.126$ & $|0.256|$ \\
\hline
\end{tabular}

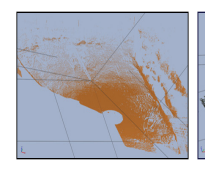

(a)

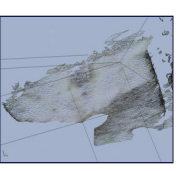

(b)

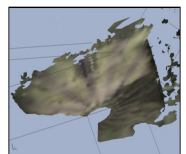

(c)

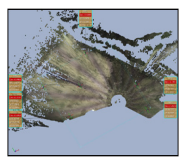

(d)
Figure 7. 3D modelling results: (a) Point cloud; (b) Polygon mesh; (c) Surface shading; (d) Distance measure

\section{CONCLUSION}

This study makes the following conclusions on the development of a 3D modeling system for earth works environments.

With respect to the performance of the field work with 3D laser scanners supplied to Korea, Scanstation II of Leica HDS showed the best performance. 
The hardware and software structures of the 3D work environment modeling system and the 3D scanning process concept in the field were designed.

The functions of a 3D work environment modeling software and user interface were designed.

The 3D work environment modeling was performed in an actual earth work environment. The maximum error in the installation of the targets and the measurement of accuracy in comparison to the total station was $29 \mathrm{~mm}$ at $76.8 \mathrm{~m}$, with an average error per meter of $0.256 \mathrm{~mm}$.

There is a plan for a more accurate test using targets with a specific interval and a new 3D scanner; and after the development of a photogrammetry module and an object recognition module by 2011, a 3D world model will be realized as the final virtualreality result of this study.

\section{ACKNOWLEDGEMENT}

This research is funded by KICTTEP Project No. 06-C4TF-C01. Authors appreciate the Youngshin Construction, Inc. for providing construction site for the experiment.

\section{REFERENCES}

[1] Ishimatsu, Y., "Introduction to the General Technology Development Project: Research and Development of an Advanced Execution Technology by Remote Control Robot and Information Technology". ISARC 2006 Proceedings, 2006. Vol. 10, pp. 24 29.

[2] Lytle, A., "Development of a Probabilistic Sensor Model for a 3D Imaging System". ISARC 2007 Proceedings, 2007. Vol. 9, pp. 75 80.

[3] El-Omari, S., "Hybrid Methodology for Automated Collection of Data from Construction Sites". ISARC 2007 Proceedings, 2007. Vol. 9, pp. 93 97. 